\title{
The in-vitro activity of tobramycin compared with that of other aminoglycosides
}

\author{
PAMELA M. WATERWORTH \\ From the Department of Microbiology, University College Hospital, London
}

SYNOPSIS The influence of medium composition, $p \mathrm{H}$, serum, and magnesium on the action of tobramycin is compared to that on the action of gentamicin. The minimum inhibitory concentration of tobramycin, gentamicin, kanamycin, and streptomycin was determined for 472 strains including 19 species: tobramycin was found to be the most active against $P$ s. aeruginosa and kanamycin against Providence, but gentamicin was usually the most active against all other species. Ps. aeruginosa passaged on medium containing either gentamicin or tobramycin showed increased resistance to both. Sensitive strains of this species were shown to contain a small minority of cells resistant to these antibiotics, the presence of which is believed to account for the marked bactericidal synergy which was demonstrated between tobramycin and carbenicillin.

Tobramycin, a new aminoglycoside antibiotic, is factor 6 of the nebramycin antibiotic complex produced by Streptomyces tenebrarius and first described in a series of papers in 1967 (Stark, Hoehn, and Knox, 1968; Higgens and Kastner, 1968; Thompson and Presti, 1968; Wick and Welles, 1968). Both these early studies and more recent work (Preston and Wick, 1970; Traub and Raymond, 1972) have shown it to have a broad antibacterial spectrum similar to that of gentamicin and to be particularly active against both Staphylococcus aureus and Ps. aeruginosa. In the present work its activity is compared to that of gentamicin, kanamycin, and streptomycin.

\section{Materials and Methods}

\section{MEDI A}

The activity of tobramycin and gentamicin was compared on Oxoid diagnostic sensitivity test agar (DST), Wellcotest agar (WA), Oxoid blood agar base no. 2 (BAB), and Oxoid nutrient broth no. 2 solidified with $1 \%$ Oxoid agar no. 3 (NA). Thereafter diagnostic sensitivity test agar was used for all tests unless otherwise stated and 5\% lysed horse blood was added for determinations of the minimum inhibitory concentration (MIC). Viable counts were done on blood agar base no. 2. Nutrient broth no. 2 (NB) was used when a fluid medium was required and tests in urine were performed with Seitz-filtered, pooled normal male urine brought to $\mathrm{pH} 6.5$ and 7.0.

Received for publication 3 October 1972.
OR GANISMS

The Salmonella, Shigella, and some of the Proteus were stock cultures, 11 strains of $S$. marscesens were received from Dr W. A. Black in London, Ontario, and eight strains of Providence from Dr L. Greenbury. The remaining organisms were fresh clinical isolates.

The MICs were determined by the plate dilution method with doubled dilutions. Plates were inoculated with a Steers, Foltz \& Graves multiple replicator using overnight broth cultures diluted to contain approximately $10^{6}$ organisms $/ \mathrm{ml}$. Tests in fluid media were done in $1 \mathrm{ml}$ volumes and inoculated with $0.02 \mathrm{ml}$ of a similar dilution. Viable counts were performed by a modified Miles and Misra technique, serial decimal dilutions being prepared by adding $0.5 \mathrm{ml}$ culture to $4.5 \mathrm{ml}$ sterile water.

Tests of combined bacteristatic action were carried out by adding a series of dilutions of each drug to agar plates, both singly and in every possible combination, and inoculating these with the multiple replicator.

Combined bactericidal action was studied by performing viable counts at intervals on broth cultures containing each drug singly and in combination, flasks being incubated in a shaking water bath at $37^{\circ} \mathrm{C}$.

\section{Results}

EFFECT OF MEDIUM

When the MIC of tobramycin and gentamicin for 33 organisms consisting mainly of $\boldsymbol{P s}$. aeruginosa, 
Klebsiella, Staph. aureus, and E. coli was determined on DST, WA, BAB, and NA, it was found that with the exception of Ps. aeruginosa, the MICs of both drugs were usually four to eight times higher on WA than on NA. Results with the other media were intermediate. With Ps. aeruginosa there was usually less difference between WA and NA (two-four-fold) and the MIC were highest on BAB.

When the MIC of these organisms was determined on medium with a low $\mathrm{Mg}$ content (NB solidified with $1 \%$ Oxoid agar no. 1) and on the same medium with $0.5 \% \mathrm{MgSO} 47 \mathrm{H}_{2} \mathrm{O}$ added, there was little difference with any organism except $P s$. aeruginosa; with this species the addition of $\mathrm{Mg}$ usually produced an eight-fold increase in the MIC of gentamicin and a four-fold increase in that of tobramycin.

EFFECT OF $p H$

The MICs of both drugs for 23 organisms were determined on DST agar brought to $p \mathrm{H} 6 \cdot 0,6 \cdot 5$, $7 \cdot 0,7 \cdot 5,8 \cdot 0$, and $8 \cdot 5$. There was no significant difference between the results with the two drugs; both were more active in alkaline medium but the differences were less than those seen with other aminoglycosides (Garrod, 1959). The results are summarized in Table I. Some tests were also done in $\mathrm{NB}$ at $p \mathrm{H} 6.5$ and 8.0 with similar results.

\begin{tabular}{llc}
\hline & Gentamicin & Tobramycin \\
\hline Staph. aureus (5) & 32 & 16 \\
E. coli (7) & 8 & 8 \\
Klebsiella spp. (3) & $2-16$ & 8 \\
Proteus spp. (3) & 16 & 8 \\
Ps. aeruginosa (5) & $8-16$ & $16-32$ \\
\hline
\end{tabular}

Table I -Fold difference in MIC on DST agar with $\mathrm{pH}$ ranging from 6.0 to 8.5

\section{EFFECT OF SERUM}

The effect of serum was studied by determining the MIC of tobramycin and gentamicin for two strains each of five species in NB with and without $50 \%$ of horse serum. The MIC of both drugs for Staph. aureus, E. coli, and Pr. mirabilis was either the same in both media (one strain) or two to four times lower in serum broth, and with $\mathrm{Kl}$. aerogenes it was either the same or twice as high. In contrast, the addition of serum produced an eight-fold increase in the MIC of both drugs for both strains of Ps. aeruginosa. The marked increase in the resistance of this species may be the result of the increased mineral content of the medium and supports the contention of Garrod and Waterworth (1969) that tests of this species with gentamicin on medium containing little $\mathrm{Mg}$ give misleading results.
TESTS IN URINE
When the MICS were determined in normal urine at $p \mathrm{H} 6.5$ and 7.0 , results with one strain each of $E$. coli 은 and $K l$. aerogenes were similar to those in broth at $\overrightarrow{\bar{B}}$ the same $p \mathrm{H}$. With four strains of Ps. aeruginosa MICs were eight times higher in urine and the same as in $50 \%$ serum broth. Both drugs were similarly affected.

EFFECT OF SIZE OF INOCULUM

When broth or agar dilution tests were inoculated with approximately $10^{9}$ organisms there was a four to eight-fold increase in resistance to both drugs in all species tested compared to that found with an inoculum of $10^{6}$ organisms.

BACTERICIDAL ACTION

All tubes in broth dilution tests which showed no growth after overnight incubation were subcultivated. Both drugs were usually found to be bactericidal at the MIC or at one tube higher, though with $P s$. aeruginosa there was sometimes growth from higher concentrations.

ANTIBACTERIAL ACTION

The antibacterial action of tobramycin on 472 strains including 19 species was compared to that of gentamicin, kanamycin, and streptomycin. The $N$ MICs are given in Tables II, III, and IV and cone⿳亠丷厂 firm the findings of other workers that tobramycin usually two to four times more active against $P S$. aeruginosa than gentamicin, but two-fold less active against other species. The rather greater difference in favour of gentamicin observed by Traub and Raymond (1971) with $S$. marsescens was also seen in this study. Both drugs were more active than either kanamycin or streptomycin against all species except Providence; 15/16 strains of this species showed some degree of resistance to both tobramycin and gentamicin and 13 of these were from two to 16 times more sensitive to kanamycin than to either of these drugs(Table III). Four strains of Alkaligenes spp. and five of Acinetobacter show considerable resistance to tobramycin and gentamicin (Table III) but the MICs of kanamycin are correspondingly higher.

The few organisms which have been found having an MIC of tobramycin or gentamicin greater than that normal for the species are listed in Table IV. Of these, two strains of Ps. aeruginosa and one of $K l$. aerogenes were isolated after treatment with gentamicin, and the $K l$. aerogenes showed an eightfold increase over the original MIC of each drug. A number of strains highly resistant to streptomycin and/or kanamycin are included in Table III. Twelve strains of Staph. aureus, two E. coli, and two 


\begin{tabular}{|c|c|c|c|c|c|}
\hline \multirow[t]{2}{*}{ Organism } & \multirow[t]{2}{*}{ No. of Strains } & \multicolumn{4}{|c|}{ Minimum Inhibitory Concentration $(\mu \mathrm{g} / \mathrm{ml})$} \\
\hline & & Gentamicin & Tobramycin & Kanamycin & Streptomycin \\
\hline $\begin{array}{l}\text { Staph. aureus } \\
\text { Str. pyogenes } \\
\text { Str. pneumoniae } \\
\text { Str. faecalis } \\
\text { H. influenzae } \\
\text { Salmonella spp. } \\
\text { Shigella spp. } \\
\text { E. coli } \\
\text { Klebsiella spp. } \\
\text { Hafnia } \\
\text { S. marcescens } \\
\text { Pr. mirabilis } \\
\text { Pr. vulgaris } \\
\text { Pr. morganii } \\
\text { Pr. rettgeri } \\
\text { Ps. aeuruginosa }\end{array}$ & $\begin{array}{r}60 \\
20 \\
6 \\
20 \\
7 \\
13 \\
25 \\
44 \\
47 \\
6 \\
20 \\
27 \\
7 \\
11 \\
6 \\
97\end{array}$ & $\begin{array}{l}0 \cdot 03-0 \cdot 06-0 \cdot 12 \\
4-8 \\
8-16 \\
2-4 \\
0 \cdot 5 \\
0 \cdot 12-0 \cdot 25 \\
0 \cdot 12-0 \cdot 25-1 \\
0 \cdot 25-0 \cdot 5-1 \\
0 \cdot 06-0 \cdot 25 \\
0-06-0 \cdot 25 \\
0 \cdot 25-0 \cdot 5 \\
0 \cdot 25-0 \cdot 5-2 \\
0 \cdot 25-0 \cdot 5 \\
0 \cdot 12-0 \cdot 25-0 \cdot 5 \\
0 \cdot 5-2 \\
0 \cdot 25-1-2\end{array}$ & $\begin{array}{l}0 \cdot 12-0 \cdot 25 \\
16 \\
16-32 \\
2-8 \\
0 \cdot 5 \\
0 \cdot 12-0 \cdot 25-1 \\
0 \cdot 12-0 \cdot 25-2 \\
0 \cdot 25-0 \cdot 5-1 \\
0 \cdot 12-0 \cdot 5-1 \\
0 \cdot 12-0 \cdot 5 \\
1-4 \\
1-4 \\
0 \cdot 25-0 \cdot 5-1 \\
0 \cdot 25-0 \cdot 5 \\
0 \cdot 25-0 \cdot 5-2 \\
0 \cdot 12-0 \cdot 25-2\end{array}$ & $\begin{array}{l}0 \cdot 5->256 \\
64-128 \\
64-128 \\
32->256 \\
0 \cdot 5-1 \\
0 \cdot 5-1-2 \\
1-2->64 \\
2->256 \\
0 \cdot 5-2->256 \\
1-2->256 \\
2->256 \\
1-2->32 \\
1-2-4 \\
1-2 \\
1-2 \\
32-256\end{array}$ & $\begin{array}{l}1-2->256 \\
32 \\
32-64 \\
32-64->256 \\
0 \cdot 25-0 \cdot 5-1 \\
1-2->64 \\
2-4->64 \\
2->256 \\
1-2->256 \\
>256 \\
2-4->256 \\
4-8->256 \\
2-4->256 \\
1->256 \\
2->256 \\
8-16-128\end{array}$ \\
\hline
\end{tabular}

Table II Minimum inhibitory concentrations of four aminoglycosides for different species of pathogenic bacteria The first figure gives the lowest inhibitory concentration for any strain. The heavy type is the usual inhibitory concentration and the third figure the highest for any strain.

\begin{tabular}{|c|c|c|c|c|c|}
\hline \multirow[t]{2}{*}{ Organism } & \multirow[t]{2}{*}{ No. of Strains } & \multicolumn{4}{|c|}{ Minimum Inhibitory Concentration $(\mu \mathrm{g} / \mathrm{ml})$} \\
\hline & & Gentamicin & Tobramycin & Kanamycin & Streptomycin \\
\hline $\begin{array}{l}\text { Providence } \\
\text { Alkaligenes spp } \\
\text { Acinetobacter }\end{array}$ & $\begin{array}{c}131 \\
4 \\
5\end{array}$ & $\begin{array}{l}2-64 \\
8->64 \\
16-64\end{array}$ & $\begin{array}{c}4-128 \\
8-128 \\
32->64\end{array}$ & $\begin{array}{c}0 \cdot 5-4 \\
32->256 \\
64->256\end{array}$ & $\begin{array}{r}8->256 \\
128->256 \\
16->256\end{array}$ \\
\hline
\end{tabular}

Table III Minimum inhibitory concentrations of four aminoglycosides for Providence Alkaligenes spp and Acinetobacter

'Excluding two strains highly resistant to all four antibiotics and 1 highly sensitive.

\begin{tabular}{|c|c|c|}
\hline & \multicolumn{2}{|c|}{ Minimum Inhibitory Concentration $(\mu \mathrm{g} / \mathrm{m} l)$} \\
\hline & Gentamicin & Tobramycin \\
\hline Staph. aureus & $\begin{array}{l}0.12 \\
0.12\end{array}$ & $\begin{array}{l}8 \\
8\end{array}$ \\
\hline Kl. aerogenes & $\begin{array}{l}8 \\
2\end{array}$ & $\begin{array}{r}16 \\
4\end{array}$ \\
\hline $\begin{array}{l}\text { Ent. aerogenes } \\
\text { Ps. aeruginosa }{ }^{1}\end{array}$ & $\begin{array}{l}0 \cdot 25 \\
4 \\
4 \\
16 \\
16 \\
8 \\
64\end{array}$ & $\begin{array}{l}8 \\
0.5 \\
05 \\
4 \\
4 \\
4 \\
32\end{array}$ \\
\hline
\end{tabular}

Table IV Minimum inhibitory concentrations of gentamicin and tobramycin for organisms showing greater than normal resistance to either

${ }^{1}$ Control strain inhibited by $1 \mu \mathrm{g} / \mathrm{ml}$ gentamicin and $0.25 \mu \mathrm{g} / \mathrm{ml}$ tobramycin.

Klebsiella were resistant to both drugs; on the other hand, of the multiple resistant Serratia received from Canada, three were resistant to streptomycin and not kanamycin and six to kanamycin but not streptomycin.

DEVELOPMENT OF RESISTANCE

Six strains of Ps. aeruginosa were transferred daily on ditch plates, containing gentamicin or tobramycin and the MICs of both drugs were determined after five and 15 transfers. After five transfers in gentamicin, the means of the -fold increase in resistance to gentamicin and tobramycin were 44 and 23 respectively, and after 15 transfers, $57 \cdot 3$ and 24 . The corresponding figures after five transfers in tobramycin were 16 and $17 \cdot 3$, and after 15 transfers, 51.6 and 31 .

It seemed probable that resistance had arisen mainly from the selection of mutants.

To confirm this Miles and Misra counts were done

\begin{tabular}{lll}
\hline$\mu g / m l$ & \multicolumn{2}{l}{ Log of Count } \\
\cline { 2 - 3 } & Gentamicin & Tobramycin \\
\hline 16 & - & - \\
8 & 1.69 & - \\
4 & 1.69 & - \\
2 & 2.60 & $2 \cdot 17$ \\
1 & 4.00 & 3.69 \\
0.5 & 6.60 & 5.3 \\
Nil & 8.47 & 8.47 \\
\hline
\end{tabular}

Table V Viable count of a broth culture of the strain of Ps. aeruginosa referred to in Fig. 1 on medium containing gentamicin or tobramycin 


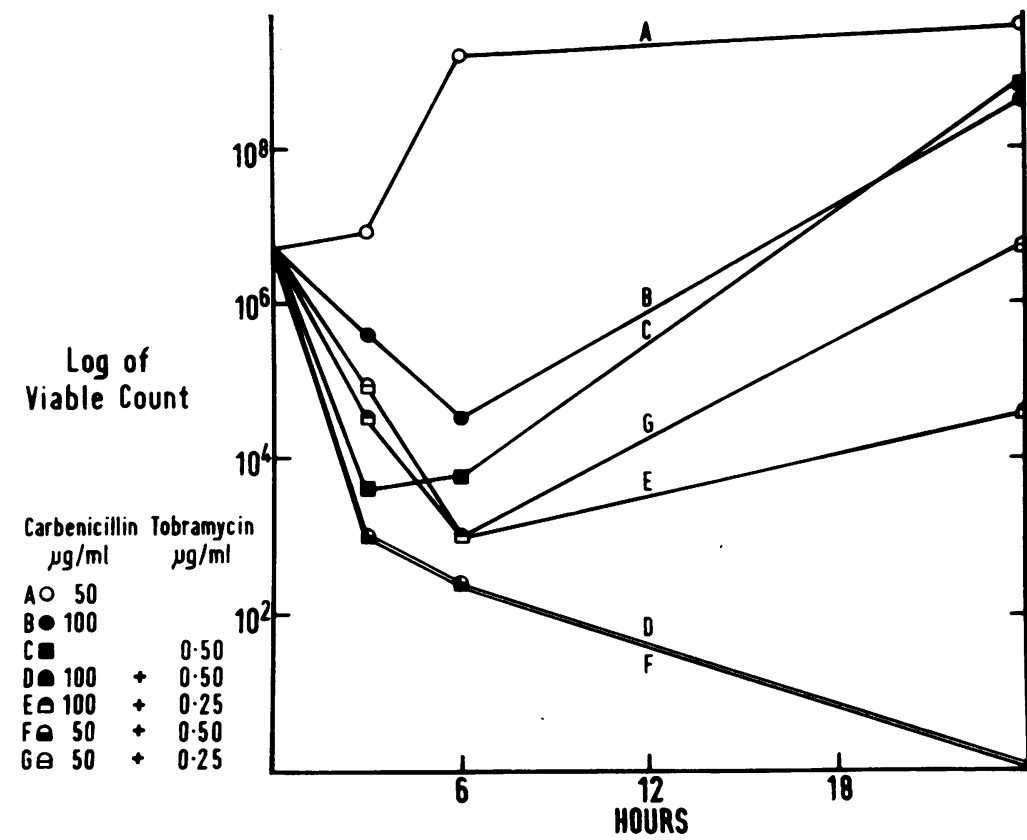

Fig. 1 Rate of death of Ps. aeruginosa in broth containing tobramycin and carbenicillin singly and together.

on an overnight broth culture of Ps. aeruginosa on plates containing increasing concentrations of gentamicin and tobramycin. The results are given in Table V. Similar results were obtained with five more strains of Ps. aeruginosa and also with the original strain from a patient whose $K l$. aerogenes became resistant during treatment with gentamicin.

\section{COMBINED ACTION}

The combined bacteristatic action of tobramycin and carbenicillin was tested by incorporating dilutions of tobramycin ranging from 2.0 to $0.06 \mu \mathrm{g} / \mathrm{ml}$ and of carbenicillin from 128 to $4 \mu \mathrm{g} / \mathrm{ml}$ singly and in all combinations in agar plates and inoculating these with 16 strains of $P$ s. aeruginosa both as undiluted overnight broth culture and culture diluted approximately $1 / 500$. With the diluted inoculum four strains showed some synergy and the remainder either an additive effect or indifference When the inoculum was heavy there was no clea synergy and with many strains the mixture was barely additive.

\section{COMBINED BACTERICIDAL ACTION}

Tests of bactericidal action were then done with one of the strains of Ps. aeruginosa against which bacteristatic synergy had been demonstrated. The results of viable counts are given in Fig. 1 and show marked synergy. Carbenicillin $50 \mu \mathrm{g} / \mathrm{ml}$ alone had no effect on growth; both carbenicillin $100 \mu \mathrm{g} / \mathrm{ml}$ and tobramycin $0.5 \mu \mathrm{g} / \mathrm{ml}$ singly reduced the count temporarily but this then rose to full growth in 24 hours. When either concentration of carbenicillin was added to $0.5 \mu \mathrm{g} / \mathrm{ml}$ tobramycin the inoculum was killed in 24 hours and the mixture remained sterile after three days' incubation. On the other hand, if

\begin{tabular}{|c|c|c|c|}
\hline \multicolumn{2}{|c|}{ Drug Concentrations Employed in Test $(\mu g / m l)$} & \multicolumn{2}{|c|}{ Subsequent MIC $(\mu \mathrm{g} / \mathrm{ml})$} \\
\hline Carbenicillin & Tobramycin & Carbenicillin & Tobramycin \\
\hline $\begin{array}{c}\overline{100} \\
50 \\
\overline{100} \\
50\end{array}$ & $\begin{array}{l}\bar{Z} \\
\bar{Z} \\
0.5 \\
0.25 \\
0.25\end{array}$ & $\begin{array}{c}64^{1} \\
256 \\
64^{1} \\
64 \\
256 \\
512\end{array}$ & $\begin{array}{l}0.5 \\
0.25 \\
0.5 \\
40 \\
1.0 \\
2.0\end{array}$ \\
\hline
\end{tabular}

Table VI MIC for Ps. aeruginosa of carbenicillin and tobramycin before and after tests of combined bactericidal action

${ }^{2}$ Partial inhibition at $32 \mu \mathrm{g} / \mathrm{ml}$ and a small number of colonies on $128 \mu \mathrm{g} / \mathrm{ml}$. 
the concentration of tobramycin was reduced to 0.25 or $0.12 \mu \mathrm{g} / \mathrm{ml}$, the counts fell until six hours but were rising again by 24 and continued to full growth by 48 hours.

The MIC of both drugs was determined for the surviving organisms in all these cultures and are stated in Table VI. A moderate increase in resistance to the antibiotics to which it had been exposed, is demonstrated in every culture in which eventual growth occurred.

\section{Discussion}

It is clear that gentamicin and tobramycin are very closely related. Gentamicin is the more active against most bacterial species, but assuming their pharmacological behaviour is similar, this may be more than offset by the greater activity of tobramycin against Ps. aeruginosa: this difference may be of even greater value with strains showing some increase in resistance to gentamicin, though it was in no case as great as that reported by Meyer, Young, and Armstrong (1971).

The activity of tobramycin against $P$ s. aeruginosa is affected by the $\mathrm{Mg}$ content of the medium in the same way as is gentamicin (Garrod and Waterworth, 1969) and the question again arises of what is the true MIC of either of these drugs for this species. Garrod and Waterworth recommend testing sensitivity by comparing the zone of inhibition produced by the unknown organism to that given by a strain of the same species of known sensitivity. Whilst this overcomes the difficulty of routine sensitivity tests, it does not help in deciding what the MIC is in vivo and hence what blood levels will be required. Meyer et al (1971) determined the MIC of tobramycin for 25 strains of Ps. aeruginosa and found from two to eight-fold differences in the results obtained on Mueller-Hinton agar and in Mueller-Hinton broth. They suggest that this difference is due to the higher $\mathrm{Mg}$ content of the agar but do not say which they believe to be the significant level. In the present study, the eight-fold increase in MIC in 50\% serum broth and in urine suggests that the higher results are the more relevant.

Darrell and Waterworth (1967) suggested that inadequate dosage of gentamicin could lead to the development of resistance in Ps. aeruginosa. The findings in Table $\mathrm{V}$ show that a culture of $P s$. aeruginosa contains a small minority of cells possessing some resistance to gentamicin and tobramycin and the degree of this corresponds to that of the small number of resistant strains which have been encountered among clinical isolates in this study. Similarly, mutants possessing greater resistance to carbenicillin are known to exist in sensitive cultures of $P s$. aeruginosa. The outgrowth of such mutants is evidently responsible for the survival of the organism in most of the tests of bactericidal action (Fig. 1), in which it has been shown that survivors from exposure to all but the lowest concentrations are less sensitive to either or both the antibiotics to which they were exposed (Table Vl). The fact that 0.5 $\mu \mathrm{g} / \mathrm{ml}$ tobramycin with either 50 or $100 \mu \mathrm{g} / \mathrm{ml}$ carbenicillin sterilizes the preparation presumably means that resistance to these concentrations of both antibiotics never coexists in a single cell. Those resistant to either can then be destroyed by the other antibiotic.

Sonne and Jawetz (1969) reported similar bactericidal synergy between carbenicillin and gentamicin but they did not determine the MIC of the surviving organisms.

I would like to thank Lilly Industries Limited for the supplies of tobramycin.

\section{References}

Darrell, J. H., and Waterworth, P. M. (1967). Dosage of gentamicin for Pseudomonas infections. Brit. med. J., 2, 535-537.

Garrod, L. P. (1959). Chemotherapy of infections of the urinary tract. Royal College of Physicians of Edinburgh, Publication No. 11, R.C.P., Edinburgh.

Garrod, L. P., and Waterworth, P. M. (1969). Effect of medium composition on the apparent sensitivity of Pseudomonas aeruginosa to gentamicin. J. clin. Path., 22, 534-538.

Higgens, C. E., and Kastner, R. E. (1967). Nebramycin, a new broad-spectrum antibiotic complex. II. Description of Streptomyces tenebrarius. Antimicrob. Agents and Chemother., pp. 324-331.

Meyer, R. D., Young, L. S., and Armstrong, D. (1971). Tobramycin (Nebramycin Factor 6); in vitro activity against Pseudomonas aeruginosa. Appl. Microbiol., 22, 1147-1151.

Preston, D. A., and Wick, W. E. (1970). Pre-clinical assessment of the anti bacterial activity of nebramycin factor 6 . Antrimicrob. Agents and Chemother., pp. 322-327.

Sonne, M., and Jawetz, E. (1969). Combined action of carbenicillin and gentamicin on Pseudomonas aeruginosa in vitro. Appl. Microbiol., 17, 893-896.

Stark, W. M., Hoehn, M. M., and Knox, N. G. (1967). Nebramycin, a new broad-spectrum antibiotic complex. I. Detection and biosynthesis. Antimicrob. Agents and Chemother., pp. 314-323.

Thompson, R. Q., and Presti, E. A. (1967). Nebramycin, a new broad-spectrum antibiotic complex. III. Isolation and chemical-physical properties. Antimicrob. Agents and Chemother., pp. 332-340.

Traub, W. H., and Raymond, E. A. (1972). Evaluation of the in vitro activity of tobramycin as compared with that of gentamicin sulphate. Appl. Microbiol., 23, 4-7.

Wick, W. E., and Welles, J. S. (1967). Nebramycin a new broadspectrum antibiotic complex. IV. In vitro and in vivo laboratory evaluation. Antimicrob. Agents and Chemother., pp. 341-348. 